\title{
Two formalisms of stochastization of one-step models
}

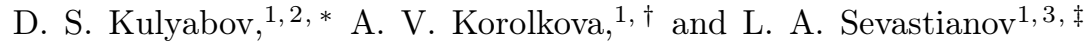 \\ ${ }^{1}$ Department of Applied Probability and Informatics, \\ Peoples' Friendship University of Russia (RUDN University), \\ 6 Miklukho-Maklaya St, Moscow, 117198, Russian Federation \\ ${ }^{2}$ Laboratory of Information Technologies \\ Joint Institute for Nuclear Research \\ 6 Joliot-Curie, Dubna, Moscow region, 141980, Russia \\ ${ }^{3}$ Bogoliubov Laboratory of Theoretical Physics \\ Joint Institute for Nuclear Research \\ 6 Joliot-Curie, Dubna, Moscow region, 141980, Russia
}

\begin{abstract}
To construct realistic mathematical models from the first principles, the authors suggest using the stochastization method. In a number of works different approaches to stochastization of mathematical models were considered. In the end, the whole variety of approaches was reduced to two formalisms: combinatorial (state vectors) and operator (occupation numbers). In the article the authors briefly describe these formalisms with an emphasis on their practical application.
\end{abstract}

Keywords: occupation numbers representation, Fock space, Dirac notation, one-step processes, master equation, diagram technique

\footnotetext{
* kulyabov_ds@rudn.university

† korolkova_av@rudn.university

$\ddagger$ sevastianov_la@rudn.university
} 


\section{INTRODUCTION}

The authors' appeal to stochastic differential equations was caused, first of all, by the desire to build mathematical models from the first principles. It turned out that many deterministic models (e.g., population models, network traffic models [1, 2]), usually obtained ad-hoc, can be represented as deterministic part of stochastic equations. These stochastic equations, in turn, are obtained from the first principles. In addition, in our opinion, the stochastic approach makes mathematical models more realistic. For example, in the Lotka-Volterra model [3], the atto-fox problem [4] is overcome.

For stochastization, the authors use two representations: representation of state vectors (combinatorial approach) and representation of occupation numbers (operator approach) [5-10].

In the combinatorial approach, all operations are performed in the space of states of the system, so we deal with a particular system throughout manipulations with the model. For the operator approach we can abstract from the specific implementation of the system under study. We are working with abstract operators. We return to the state space only at the end of the calculations. In addition, we choose a particular operator algebra on the basis of symmetry of the problem.

To construct stochastic models, we use the apparatus of interaction schemes. Based on the interaction schemes, we have constructed a diagram formalism for the operator approach.

In this article, the authors tried to give the main points of the combinatorial and operator approaches in such a way that they could be easily used in practical problems.

The structure of the article is as follows. In the section II basic notations and conventions are introduced. Then the interaction schemes are presented in the next section III. The combinatorial method of modelling is discussed in

the following section IV. The operator model approach is presented in the section V] Application of this technique is described in section VI on the example of Verhulst model.

\section{NOTATIONS AND CONVENTIONS}

1. The abstract indices notation (see [11]) is used in this work. Under this notation a tensor as a whole object is denoted just as an index (e.g., $x^{i}$ ), components are denoted by underlined index (e.g., $x^{i}$ ).

2. We will adhere to the following agreements. Latin indices from the middle of the alphabet $(i, j, k)$ will be applied to the space of the system state vectors. Latin indices from the beginning of the alphabet $(a)$ will be related to the Wiener process space. Greek indices $(\alpha)$ will set a number of different interactions in kinetic equations.

\section{INTERACTION SCHEMES}

Schemes of interaction are similar to the schemes of chemical kinetics [12, 13], which however have somewhat different semantics.

The system state is defined by the vector $\varphi^{i} \in \mathbb{R}^{n}$, where $n$ is system dimension. The operator $I_{j}^{i} \in \mathbb{N}_{0}^{n} \times \mathbb{N}_{0}^{n}$ describes the state of the system before the interaction, the operator $F_{j}^{i} \in \mathbb{N}_{0}^{n} \times \mathbb{N}_{0}^{n}$ describes the state of the system after the interaction. The result of interaction is the system transition from one state to another one:

$$
I_{j}^{i} \varphi^{j} \stackrel{{ }^{+} k}{\rightleftharpoons} F_{j}^{i} \varphi^{j}
$$

The coefficients ${ }^{+} k$ and ${ }^{-} k$ are the intensities of interaction.

There are $s$ types of interaction in our system, so instead of $I_{j}^{i}$ and $F_{j}^{i}$ operators we will use operators $I_{j}^{i \alpha} \in$ $\mathbb{N}_{0}^{n} \times \mathbb{N}_{0}^{n} \times \mathbb{N}_{+}^{s}$ and $F_{j}^{i \alpha} \in \mathbb{N}_{0}^{n} \times \mathbb{N}_{0}^{n} \times \mathbb{N}_{+}^{s}$ :

$$
I_{j}^{i \underline{\alpha}} \varphi^{j} \underset{{ }_{{ }_{\underline{\underline{\alpha}}}}}{\stackrel{{ }_{k_{\underline{\alpha}}}}{\rightleftharpoons}} F_{j}^{i \underline{\alpha}} \varphi^{j}, \quad \underline{\alpha}=\overline{1, s}
$$

the Greek indices specify the number of interactions and the Latin indices correspond to the system order. 
Usually, the diagonal operators $I$ and $F$ are used. That is, they can be formally represented as a vector for each reaction. Then the system (1) takes the following form:

$$
I_{j}^{\alpha} \varphi^{j} \stackrel{{ }^{+}{ }_{\underline{\alpha}}}{\underset{{ }_{{ }_{\underline{\alpha}}}}{\rightleftharpoons}} F_{j}^{\alpha} \varphi^{j}
$$

Here the following notation is used:

$$
I_{j}^{\alpha}:=I_{j}^{i \alpha} \delta_{i}, \quad F_{j}^{\alpha}:=F_{j}^{i \alpha} \delta_{i}
$$

where $\delta_{i}=(1, \ldots, 1)$.

In the combinatorial approach, the state transition operator is important:

$$
r_{j}^{i \underline{\alpha}}=F_{j}^{i \underline{\alpha}}-I_{j}^{i \underline{\alpha}}, \quad r_{j}^{\underline{\alpha}}:=r_{j}^{i \underline{\alpha}} \delta_{i}=F_{j}^{\underline{\alpha}}-I_{j}^{\underline{\alpha}} .
$$

\section{COMBINATORIAL APPROACH}

In the combinatorial approach for the system description we will use the master equation, which describes the transition probabilities for Markov process (see [14, 15]).

$$
\frac{\partial p\left(\varphi_{2}, t_{2} \mid \varphi_{1}, t_{1}\right)}{\partial t}=\int\left[w\left(\varphi_{2} \mid \psi, t_{2}\right) p\left(\psi, t_{2} \mid \varphi_{1}, t_{1}\right)-w\left(\psi \mid \varphi_{2}, t_{2}\right) p\left(\varphi_{2}, t_{2} \mid \varphi_{1}, t_{1}\right)\right] \mathrm{d} \psi,
$$

where $w(\varphi \mid \psi, t)$ is the probability of transition from the state $\psi$ to the state $\varphi$ per unit time.

By fixing the initial values of $\varphi_{1}, t_{1}$, we can write the equation for subensemble:

$$
\frac{\partial p(\varphi, t)}{\partial t}=\int[w(\varphi \mid \psi, t) p(\psi, t)-w(\psi \mid \varphi, t) p(\varphi, t)] \mathrm{d} \psi
$$

For the discrete domain of $\varphi$, the (3) can be written as follows (the states are numbered by $n$ and $m$ ):

$$
\frac{\partial p_{n}(t)}{\partial t}=\sum_{m}\left[w_{n m} p_{m}(t)-w_{m n} p_{n}(t)\right]
$$

where the $p_{n}$ is the probability of the system to be in a state $n$ at time $t, w_{n m}$ is the probability of transition from the state $m$ into the state $n$ per unit time.

There are two types of system transition from one state to another (based on one-step processes) as a result of system elements interaction: in the forward direction $\left(\varphi^{i}+r^{i \alpha}\right)$ with the probability ${ }^{+} s_{\alpha}\left(\varphi^{k}\right)$ and in the opposite direction $\left(\varphi^{i}-r^{i \alpha}\right)$ with the probability ${ }^{-} s_{\underline{\alpha}}\left(\varphi^{k}\right)$. The matrix of transition probabilities has the form:

$$
w_{\underline{\alpha}}\left(\varphi^{i} \mid \psi^{i}, t\right)={ }^{+}{ }_{\underline{\alpha}} \delta_{\varphi^{i}, \psi^{i}+1}+{ }^{-}{ }_{\underline{\alpha}} \delta_{\varphi^{i}, \psi^{i}-1}, \quad \underline{\alpha}=\overline{1, s}
$$

where $\delta_{i, j}$ is Kronecker delta.

Thus, the general form of the master equation for the state vector $\varphi^{i}$, changing by steps with length $r^{i \alpha}$, is:

$$
\begin{aligned}
\frac{\partial p\left(\varphi^{i}, t\right)}{\partial t}= & \sum_{\underline{\alpha}=1}^{s}\left\{{ }^{-} s_{\underline{\alpha}}\left(\varphi^{i}+r^{i \underline{\alpha}}, t\right) p\left(\varphi^{i}+r^{i \underline{\alpha}}, t\right)+\right. \\
& \left.\quad+{ }^{+} s_{\underline{\alpha}}\left(\varphi^{i}-r^{i \alpha}, t\right) p\left(\varphi^{i}-r^{i \alpha}, t\right)-\left[{ }^{+} s_{\underline{\alpha}}\left(\varphi^{i}\right)+{ }^{-} s_{\underline{\alpha}}\left(\varphi^{i}\right)\right] p\left(\varphi^{i}, t\right)\right\}
\end{aligned}
$$

In the combinatorial approach we don't use the master equation itself. Instead, we use the Fokker-Planck equation and the Langevin equation.

The Fokker-Planck equation is a special case of the master equation and can be regarded as its approximation. We can get through the expansion of the master equation in a series up to the second order. To do this, one can use the so-called Kramers-Moyal expansion [15]. 
The Fokker-Planck equation has the following form:

$$
\frac{\partial p\left(\varphi^{k}, t\right)}{\partial t}=-\frac{\partial}{\partial \varphi^{i}}\left[A^{i}\left(\varphi^{k}\right) p\left(\varphi^{k}, t\right)\right]+\frac{1}{2} \frac{\partial^{2}}{\partial \varphi^{i} \partial \varphi^{j}}\left[B^{i j}\left(\varphi^{k}\right) p\left(\varphi^{k}, t\right)\right],
$$

The Langevin equation which corresponds to the Fokker-Planck equation:

$$
\mathrm{d} \varphi^{i}=a^{i} \mathrm{~d} t+b_{a}^{i} \mathrm{~d} W^{a},
$$

where $a^{i}:=a^{i}\left(\varphi^{k}\right), b_{a}^{i}:=b_{a}^{i}\left(\varphi^{k}\right), \varphi^{i} \in \mathbb{R}^{n}$ is the system state vector, $W^{a} \in \mathbb{R}^{m}$ is the $m$-dimensional Wiener process. Latin indices from the middle of the alphabet will be applied to the system state vectors (the dimensionality of space is $n$ ), and Latin indices from the beginning of the alphabet denote the variables related to the Wiener process vector (the dimensionality of space is $m \leqslant n$ ).

The relation between the equations (6) and (7) is expressed by the following relationships:

$$
A^{i}=a^{i}, \quad B^{i j}=b_{a}^{i} b^{j a} .
$$

We will obtain the function ${ }^{+} s_{\underline{\alpha}}$ and ${ }^{-} s_{\underline{\alpha}}$ with use of combinatorial considerations. The transition rates ${ }^{+} s_{\underline{\alpha}}$ and ${ }^{-} s_{\underline{\alpha}}$ are proportional to the number of ways of choosing the number of arrangements of $\varphi^{\underline{i}}$ to $I_{-}^{i \underline{\alpha}}$ (denoted as $A_{\varphi-\underline{i}}^{I^{i} \underline{\underline{\alpha}}}$ ) and to $F_{-}^{i} \underline{\underline{\alpha}}$ (denoted as $A_{\varphi \underline{\underline{i}}}^{F \underline{\underline{i}} \underline{\alpha}}$ ) and defined by:

$$
\begin{aligned}
& { }^{+} s_{\underline{\alpha}}={ }^{+} k_{\underline{\alpha}} \prod_{\underline{i}=1}^{n} A_{\varphi \underline{\underline{i}}}^{I \underline{i} \underline{\underline{\alpha}}}={ }^{+} k_{\underline{\alpha}} \prod_{\underline{i}=1}^{n} \frac{\varphi^{\underline{i}} \underline{!}}{\left(\varphi^{-}-I^{i} \underline{\underline{\alpha}}\right) !}, \\
& { }^{-} s_{\underline{\alpha}}={ }^{-} k_{\underline{\alpha}} \prod_{\underline{i}=1}^{n} A_{\varphi \underline{\underline{i}}}^{F^{\underline{i}} \underline{\alpha}}={ }^{-} k_{\underline{\alpha}} \prod_{\underline{i}=1}^{n} \frac{\varphi^{\underline{i}} !}{\left(\varphi^{\underline{i}}-F^{\underline{i}} \underline{\alpha}\right) !} .
\end{aligned}
$$

Since the Fokker-Planck equation is a consequence of the expansion of the master equation and by discarding small terms, we will make an appropriate replacement in the equation (9). Namely, combinations of the type $\varphi(\varphi-$ $1) \cdots(\varphi-(n-1))$ will be replaced by $(\varphi)^{n}$ :

$$
\begin{aligned}
& { }_{\mathrm{fp}^{+}} s_{\underline{\alpha}}={ }^{+} k_{\underline{\alpha}} \prod_{\underline{i}=1}^{n}\left(\varphi^{\underline{i}}\right)^{I^{\underline{i}}-\underline{\alpha}}, \\
& { }_{\mathrm{fp}} s_{\underline{\alpha}}={ }^{-} k_{\underline{\alpha}} \prod_{\underline{i}=1}^{n}\left(\varphi^{-}\right)^{F-\underline{\alpha}} .
\end{aligned}
$$

Then for the Fokker-Planck equation (6) we may obtain formulas for the coefficients:

$$
\begin{aligned}
& A^{i}:=A^{i}\left(\varphi^{k}\right)=r^{i \underline{\alpha}}\left[{ }_{\mathrm{fp}^{+}}^{+} s_{\underline{\alpha}}-{ }_{\mathrm{fp}^{-}}^{-} s_{\underline{\alpha}}\right],
\end{aligned}
$$

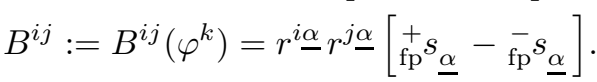

Using the relation (8), we may obtain the coefficients for the Langevin equation (17) from the relations (10).

\section{OPERATOR APPROACH}

The method of application of the second quantization formalism for the non-quantum systems (statistical, deterministic systems) was studied in a series of articles (see [7, 16 18]). The Dirac notation is commonly used for occupation numbers representation recording.

The transition to the space of occupation numbers is not a unitary transformation. However, the algorithm of transition can be constructed.

Let's write the master equation (4) in the occupation number representation. We will consider a system that does not depend on the spatial variables. For simplicity, we consider the one-dimensional version.

Let's denote in (4) the probability that there are $n$ particles in our system as $\varphi_{n}$ :

$$
\varphi_{n}:=p_{n}(\varphi, t)
$$




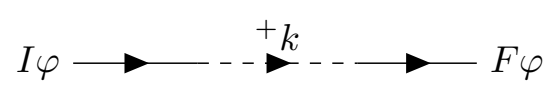

Figure 1. Forward interaction

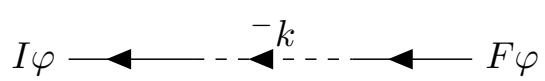

Figure 2. Backward interaction

The vector space $\mathcal{H}$ consists of states of $\varphi$.

Depending on the structure of the model, we can introduce the probability-based or the moment-based inner products [7]. We introduce a scalar product, exclusive $\left(\langle\mid\rangle_{\mathrm{ex}}\right)$ and inclusive $\left(\langle\mid\rangle_{\mathrm{in}}\right)$. Let $|n\rangle$ be the basis vectors.

$$
\begin{aligned}
\langle\varphi \mid \psi\rangle_{\mathrm{ex}} & =\sum_{n} n ! p_{n}^{*}(\varphi) p^{n}(\psi) ; \\
\langle\varphi \mid \psi\rangle_{\text {in }} & =\sum_{n} \frac{1}{k !} n_{k}^{*}(\varphi) n^{k}(\psi) .
\end{aligned}
$$

Here $n_{k}$ are factorial moments:

$$
n_{k}(\varphi)=\langle n(n-1) \cdots(n-k+1)\rangle=\left.\frac{\partial^{k}}{\partial z^{k}} G(z, \varphi)\right|_{z=1},
$$

$G$ is generating function:

$$
G(z, \varphi)=\sum_{n} z^{n} p_{n}(\varphi)
$$

Let's introduce creation and annihilation operators:

and commutation rule1:

$$
\begin{gathered}
\pi|n\rangle=|n+1\rangle, \\
a|n\rangle=n|n-1\rangle
\end{gathered}
$$

$$
[a, \pi]=1 .
$$

If the form of scalar product is (11) then from (12) follows that our system is described by the Bose-Einstein statistics.

In the occupation numbers formalism the master equation becomes the Liouville equation:

$$
\frac{\partial}{\partial t}|\varphi(t)\rangle=L|\varphi(t)\rangle
$$

The Liouville operator $L$ satisfies the relation:

$$
\langle 0| L=0 .
$$

We will describe our proposed diagram technique for the stochastization of one-step processes.

We will write the the scheme of interaction in the form of diagrams. Each scheme (11) or (2) corresponds to a pair of diagrams (see fig. 1 and 2) for forward and backward interaction respectively. The diagram consists of the following elements.

- Incoming lines (in the fig. 1 are denoted by the solid line). These lines are directed to the line of interaction. These lines are marked with the number and type of interacting entities. You can write a single entity per a line or group them.

- Outgoing lines (in the fig. 1 are denoted by the solid line). These lines are directed from the line of interaction. These lines are marked with the number and type of interacting entities. You can write a single entity per a line or group them.

- Line of interaction (in the fig. 1 is denoted by the dotted line). The direction of time is denoted by the arrow. This line is marked by the coefficient of rate of the interaction.

\footnotetext{
${ }^{1}$ In fact, $a \pi|n\rangle-\pi a|n\rangle=(n+1)|n\rangle-n|n\rangle=|n\rangle$.
} 


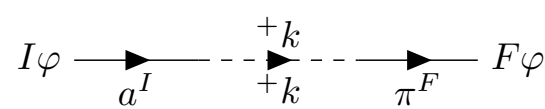

Figure 3. Forward interaction

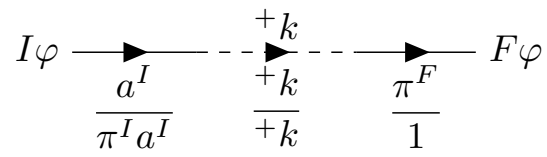

Figure 5. Forward interaction, extended notation

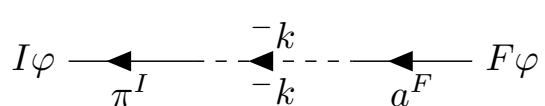

Figure 4. Backward interaction

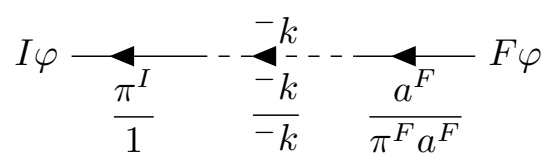

Figure 6. Backward interaction, extended notation

Each line is attributed to a certain factor (depending on the the approach chosen). The resulting expression is obtained by multiplying these factors.

We obtain the Liouville operator when using interaction diagrams in the operator approach. Let us assign the corresponding factor for each line. The resulting term is obtained as the normal ordered product of factors.

We use the following factors for each type of line (Fig. 3, ).

- Incoming line. This line corresponds to the disappearance of one entity from the system. Therefore, it corresponds to the annihilation operator $a$. It is clear that the line with combined capacity $I$ corresponds to the operator $a^{I}$.

- Outgoing line. This line corresponds to the emergence of one entity in the system. Therefore, it corresponds to the creation operator $\pi$. It is clear that the line with combined capacity $F$ corresponds to the operator $\pi^{F}$.

- Line of interaction. This line corresponds to the ratio of the interaction rate.

That is, for the diagram 3 we obtain a factor ${ }^{+} k \pi^{F} a^{I}$. However, this violates the equation (13). Redressing this, we have to subtract the number of entities that have entered into interaction, multiplied by the rate of the interaction. Then we get a following term of the Liouville operator:

$$
{ }^{+} k \pi^{F} a^{I}-{ }^{+} k \pi^{I} a^{I}={ }^{+} k\left(\pi^{F}-\pi^{I}\right) a^{I} .
$$

To backward interactions (fig. 44), we use the same rules.

To account for the additional factor of (14) we will use the extended diagrams (fig. 5 and 6). Here, from the the normal ordered product of the numerators the normal product of the denominators is subtracted.

Thus, the following Liouville operator corresponds to the scheme (1):

$$
L=\sum_{\underline{\alpha}, \underline{i}}\left[{ }^{+} k_{\underline{\alpha}}\left(\left(\pi_{\underline{i}}\right)^{F \underline{i} \underline{\alpha}}-\left(\pi_{\underline{i}}\right)^{I^{\underline{i} \underline{\alpha}}}\right)\left(a_{\underline{i}}\right)^{I-\underline{\underline{\alpha}}}+{ }^{-} k_{\underline{\alpha}}\left(\left(\pi_{\underline{i}}\right)^{I-\underline{\underline{\alpha}}}-\left(\pi_{\underline{i}}\right)^{F \underline{\underline{i}} \underline{\alpha}}\right)\left(a_{\underline{i}}\right)^{F \underline{\underline{i}} \underline{\alpha}}\right] .
$$

\section{VERHULST MODEL}

As a demonstration of the method, we will consider the Verhulst model [3, 19, 20], which describes the limited growth. The attractiveness of this model is that it is one-dimensional and non-linear. Initially, this model was written down as the differential equation:

$$
\frac{\mathrm{d} \varphi}{\mathrm{d} t}=\lambda \varphi-\beta \varphi-\gamma \varphi^{2},
$$

where $\lambda$ denotes the breeding rate factor, $\beta$ is the extinction rate factor, $\gamma$ is the factor of population reduction rate (usually the rivalry of individuals is considered). The same notation as in the original model [19] is used.

The interaction scheme for the stochastic version of the model is:

$$
\begin{gathered}
\varphi \stackrel{\lambda}{\stackrel{\lambda}{\rightleftharpoons}} 2 \varphi, \\
\varphi \stackrel{\beta}{\rightarrow} 0 .
\end{gathered}
$$




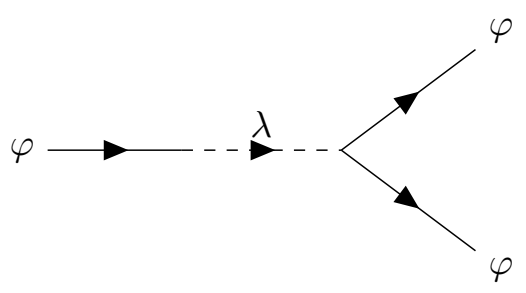

Figure 7. First forward interaction
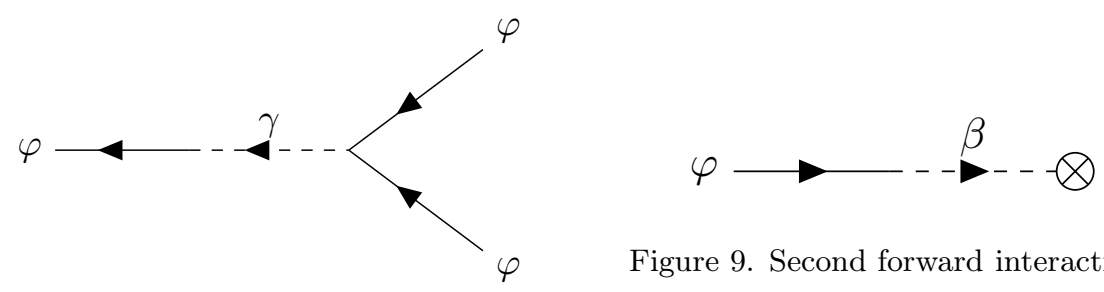

Figure 9. Second forward interaction

Figure 8. First backward interaction

The interaction schemes (16) match diagrams 7 , 8 , and 9 ,

The first relation means that an individual who eats one unit of meal is immediately reproduced, and in the opposite direction is the rivalry between individuals. The second relation describes the death of an individual.

\section{A. Combinatorial approach}

Let's define transition rates within the Verhults model as follows:

$$
\begin{array}{ccc}
{ }^{+} s_{1}(\varphi)=\lambda \varphi, & { }^{+} s_{1}(\varphi-1)=\lambda(\varphi-1), & { }^{+} s_{1}(\varphi+1)=\lambda(\varphi+1), \\
{ }^{-} s_{1}(\varphi)=\gamma \varphi(\varphi-1), & { }^{-} s_{1}(\varphi-1)=\gamma(\varphi-1)(\varphi-2), & { }^{-} s_{1}(\varphi+1)=\gamma(\varphi+1) \varphi, \\
{ }^{+} s_{2}(\varphi)=\beta \varphi . & { }^{+} s_{2}(\varphi-1)=\beta(\varphi-1) . & { }^{+} s_{2}(\varphi+1)=\beta(\varphi+1) . \\
r^{1}=1, \quad r^{2}=-1 . &
\end{array}
$$

Then, based on (5), the form of the master equation is:

$$
\frac{\partial p(\varphi, t)}{\partial t}=-[\lambda \varphi+\beta \varphi+\gamma \varphi(\varphi-1)] p(\varphi, t)+[\beta(\varphi+1)+\gamma(\varphi+1) \varphi] p(\varphi+1, t)+\lambda(\varphi-1) p(\varphi-1, t) .
$$

For particular values of $\varphi=n$ (see Eq. (44)):

$$
\begin{aligned}
\frac{\partial p_{n}(t)}{\partial t}:=\left.\frac{\partial p(\varphi, t)}{\partial t}\right|_{\varphi=n} & = \\
& =-[\lambda n+\beta n+\gamma n(n-1)] p_{n}(t)+[\beta(n+1)+\gamma(n+1) n] p_{n+1}(t)+\lambda(n-1) p_{n-1}(t) .
\end{aligned}
$$

\section{B. Operator approach}

The interaction schemes (16) in the operator approach match diagrams 10, 11, and 12 ,

From (16) and (15) the Liouville operator is:

$$
\begin{aligned}
& L=\lambda\left(\pi^{2}-\pi\right) a+\gamma\left(\pi-\pi^{2}\right) a^{2}+\beta(1-\pi) a= \\
& =\lambda\left(\left(a^{\dagger}\right)^{2}-a^{\dagger}\right) a+\gamma\left(a^{\dagger}-\left(a^{\dagger}\right)^{2}\right) a^{2}+\beta\left(1-a^{\dagger}\right) a= \\
& =\lambda\left(a^{\dagger}-1\right) a^{\dagger} a+\beta\left(1-a^{\dagger}\right) a+\gamma\left(1-a^{\dagger}\right) a^{\dagger} a^{2} .
\end{aligned}
$$

The master equation by the Liouville operator:

$$
\begin{aligned}
& \frac{\partial p_{n}(t)}{\partial t}=\frac{1}{n !}\langle n|L| \varphi\rangle= \\
&=\frac{1}{n !}\langle n|-\left[\lambda a^{\dagger} a\right.\left.+\beta a^{\dagger} a+\gamma a^{\dagger} a^{\dagger} a a\right]+\left[\beta a+\gamma a^{\dagger} a a\right]+\lambda a^{\dagger} a^{\dagger} a|\varphi\rangle= \\
&=-[\lambda n+\beta n+\gamma n(n-1)]\langle n \mid \varphi\rangle+ \\
&+[\beta(n+1)+\gamma(n+1) n]\langle n+1 \mid \varphi\rangle+\lambda(n-1)\langle n-1 \mid \varphi\rangle= \\
&=-[\lambda n+\beta n+\gamma n(n-1)] p_{n}(t)+ \\
& \quad+[\beta(n+1)+\gamma(n+1) n] p_{n+1}(t)+\lambda(n-1) p_{n-1}(t) .
\end{aligned}
$$

The result (18) coincides with the formula (17), which was obtained by combinatorial method. 


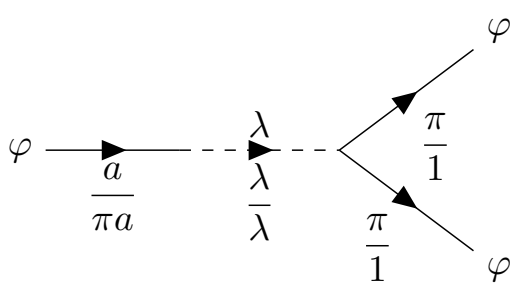

Figure 10. First forward interaction

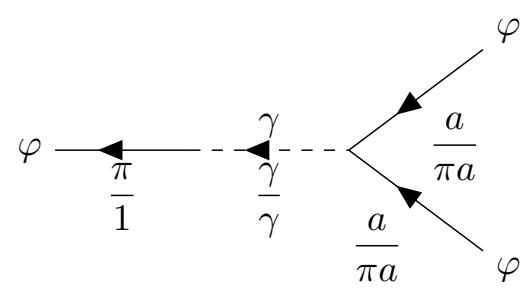

Figure 11. First backward interaction

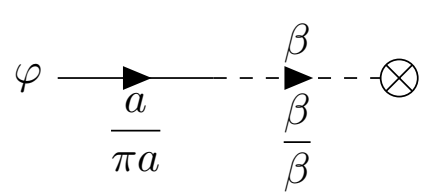

Figure 12. Second forward interaction

\section{CONCLUSIONS}

The described stochastization methods make it possible to obtain a specific form of both the Liouville operator and self-consistent stochastic differential equations in the form of Langevin and Fokker-Planck. The authors hope that the proposed diagram technique will simplify the derivation of the Liouville operator in the representation of occupation numbers.

\section{ACKNOWLEDGMENTS}

The publication has been prepared with the support of the "RUDN University Program 5-100" and funded by Russian Foundation for Basic Research (RFBR) according to the research projects No 16-07-00556 and 18-07-00567.

[1] A. V. Demidova, A. V. Korolkova, D. S. Kulyabov, L. A. Sevastyanov, The Method of Constructing Models of Peer to Peer Protocols, in: 6th International Congress on Ultra Modern Telecommunications and Control Systems and Workshops (ICUMT), IEEE Computer Society, 2015, pp. 557-562. arXiv:1504.00576, doi:10.1109/ICUMT.2014.7002162

[2] T. R. Velieva, A. V. Korolkova, D. S. Kulyabov, Designing Installations for Verification of the Model of Active Queue Management Discipline RED in the GNS3, in: 6th International Congress on Ultra Modern Telecommunications and Control Systems and Workshops (ICUMT), IEEE Computer Society, 2015, pp. 570-577. arXiv:1504.02324 doi:10.1109/ICUMT .2014.7002164.

[3] W. Feller, Die Grundlagen der Volterraschen Theorie des Kampfes ums Dasein in wahrscheinlichkeitstheoretischer Behandlung, Acta Biotheoretica 5 (1) (1939) 11-40. doi:10.1007/BF01602932.

[4] D. Mollison, Dependence of epidemic and population velocities on basic parameters, Mathematical Biosciences 107 (2) (1991) 255-287. doi:10.1016/0025-5564(91)90009-8

[5] A. V. Korolkova, E. G. Eferina, E. B. Laneev, I. A. Gudkova, L. A. Sevastianov, D. S. Kulyabov, Stochastization Of One-Step Processes In The Occupations Number Representation, Proceedings 30th European Conference on Modelling and Simulation (2016) 698-704doi:10.7148/2016-0698

[6] M. Hnatič, E. G. Eferina, A. V. Korolkova, D. S. Kulyabov, L. A. Sevastyanov, Operator Approach to the Master Equation for the One-Step Process, EPJ Web of Conferences 108 (2016) 58-59. arXiv:1603.02205 doi:10.1051/epjconf/201610802027

[7] P. Grassberger, M. Scheunert, Fock-Space Methods for Identical Classical Objects, Fortschritte der Physik 28 (10) (1980) 547-578. doi:10.1002/prop.19800281004.

[8] U. C. Täuber, Field-Theory Approaches to Nonequilibrium Dynamics, in: Ageing and the Glass Transition, Vol. 716, Springer Berlin Heidelberg, Berlin, Heidelberg, 2005, pp. 295-348. arXiv:0511743, doi:10.1007/3-540-69684-9_7.

[9] H.-K. Janssen, U. C. Täuber, The field theory approach to percolation processes, Annals of Physics 315 (1) (2005) 147-192. arXiv:0409670 doi:10.1016/j.aop.2004.09.011.

[10] M. Mobilia, I. T. Georgiev, U. C. Täuber, Fluctuations and correlations in lattice models for predator-prey interaction, Physical Review E 73 (4) (2006) 040903. arXiv:0508043, doi:10.1103/PhysRevE.73.040903

[11] R. Penrose, W. Rindler, Spinors and Space-Time: Volume 1, Two-Spinor Calculus and Relativistic Fields, Vol. 1, Cambridge University Press, 1987. doi:10.1017/CB09780511564048.

[12] P. Waage, C. M. Gulberg, Studies concerning affinity, J. Chem. Educ. 63 (12) (1986) 1044. doi:10.1021/ed063p1044

[13] A. N. Gorban, G. S. Yablonsky, Three Waves of Chemical Dynamics, Math. Model. Nat. Phenom. Vol. 10 (5) (2015) 1-5. doi:10.1051/mmp/201510501

[14] N. G. van Kampen, Stochastic Processes in Physics and Chemistry, North-Holland Personal Library, Elsevier Science, 2011.

[15] C. W. Gardiner, Handbook of Stochastic Methods: for Physics, Chemistry and the Natural Sciences, Springer Series in Synergetics, 1985. 
[16] M. Doi, Second quantization representation for classical many-particle system, Journal of Physics A: Mathematical and General 9 (9) (1976) 1465-1477. doi:10.1088/0305-4470/9/9/008.

[17] M. Doi, Stochastic theory of diffusion-controlled reaction, Journal of Physics A: Mathematical and General 9 (9) (1976) 1479-1495. doi:10.1088/0305-4470/9/9/009.

[18] L. Peliti, Path integral approach to birth-death processes on a lattice, Journal de Physique 46 (9) (1985) $1469-1483$. doi:10.1051/jphys:019850046090146900.

[19] P. F. Verhulst, Notice sur la loi que la population suit dans son accroissement, Vol. 10, 1838.

[20] W. Feller, On the theory of stochastic processes, with particular reference to applications, Proceedings of the [First] Berkeley Symposium on Mathematical Statistics and Probability (1949) 403-432. 


\title{
Два формализма стохастизации одношаговых моделей
}

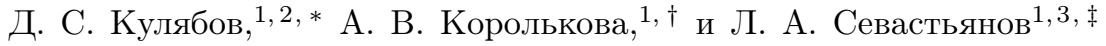 \\ ${ }^{1}$ Кафедра прикладной информатики и теории вероятностей, \\ Российский университет дружбы народов, \\ 117198, Москва, ул. Миклухо-Маклая, д. 6 \\ 2 Лаборатория информационных технологий, \\ Объединённый институт ядерных исследований, \\ ул. Жолио-Кюри 6, Дубна, Московская область, Россия, 141980 \\ 3 Лаборатория теоретической физики, \\ Объединённый институт ядерных исследований, \\ ул. Жолио-Кюри 6, Дубна, Московская область, Россия, 141980
}

Для построения реалистичных математических моделей из первых принципов авторы предлагают использовать метод стохастизации. В ряде работ были рассмотрены разные подходы к стохастизации математических моделей. В конечном счёте всё многообразие подходов было сведено к двум формализмам: комбинаторному (векторов состояний) и операторному (чисел заполнения). В статье авторы кратко описывают эти формализмы с упором на их практическое применение.

Ключевыеслова: представление чисел заполнения, пространство Фока, нотация Дирака, одношаговые процессы, основное кинетическое уравнение, диаграммная техника

\footnotetext{
* kulyabov_ds@rudn.university

$\dagger$ korolkova_av@rudn.university

$\ddagger$ sevastianov_la@rudn.university
} 


\section{I. ВВЕДЕНИЕ}

Обращение авторов к стохастическим дифференциальным уравнениям было вызвано, в первую очередь, желанием строить математические модели из первых принципов. Оказалось, что многие детерминистические модели (например, популяционные модели, модели сетевого трафика [1, 2]), обычно получаемые аd-hос, можно представить как детерминистическую часть стохастических уравнений. Эти стохастические уравнения, в свою очередь, получаются из первых принципов. Кроме того, по нашему мнению, стохастический подход делает математические модели более реалистичными. Например, в модели Лотки-Вольтерры [3] преодолевается атто-лисья проблема [4].

Для стохастизации авторы используют два представления: представление векторов состояния (комбинаторный подход) и представление чисел заполнения (операторный подход) [5 10].

В комбинаторном подходе все действия выполняются в пространстве векторов состояния системы, то есть мы на протяжении всех модельных манипуляций имеем дело с конкретной исследуемой системой. В операторном подходе мы отвлекаемся от конкретной реализации исследуемой системы, работая с абстрактными операторами. В пространство векторов состояний мы переходим только в конце вычислений. Кроме того, конкретную операторную алгебру мы выбираем, исходя их симметрии задачи.

Для конструирования стохастических моделей нами используется аппарат схем взаимодействия. На основе схем взаимодействия нами построен диаграммный формализм для операторного подхода.

В данной статье авторы постарались дать основные моменты комбинаторного и операторного подходов таким образом, чтобы их можно было легко использовать в практических задачах.

Структура статьи следующая. В разделе П введены основные обозначения и соглашения. В разделе ПI вводятся схемы взамодействия. В разделе IV описывается комбинаторный модельный подход. В разделе V даётся операторный модельный подход и диаграммная техника. В разделе VI демонстрируется применение описанных подходов на примере модели Ферхюльста.

\section{II. ОБОЗНАЧЕНИЯ И СОГЛАШЕНИЯ}

1. В работе используется нотация абстрактных индексов [11]. В данной нотации тензор как целостный объект обозначается просто индексом (например, $x^{i}$ ), компоненты обозначаются подчёркнутым индексом (напримep, $x-i)$.

2. Будем придерживаться следующих соглашений. Латинские индексы из середины алфавита $(i, j, k)$ будут относиться к пространству векторов состояний системы. Латинские индексы из начала алфавита $(a)$ будут относиться к пространству винеровского процесса. Греческие индексы $(\alpha)$ будут задавать количество разных взаимодействий в кинетических уравнениях.

\section{III. СХЕМЫ ВЗАИМОДЕЙСТВИЯ}

Схемы взаимодействия подобны схемам химической кинетики [12, 13], которые, впрочем, имеют несколько другую семантику.

Состояние системы будем описывать вектором состояния $\varphi^{i} \in \mathbb{R}^{n}$, где $n-$ размерность системы. Оператор $I_{j}^{i} \in \mathbb{N}_{0}^{n} \times \mathbb{N}_{0}^{n}$ задаёт состояние системы до взаимодействия, оператор $F_{j}^{i} \in \mathbb{N}_{0}^{n} \times \mathbb{N}_{0}^{n}-$ после. В результате взаимодействия происходит переход системы в другое состояние:

$$
I_{j}^{i} \varphi^{j} \underset{{ }_{-k}}{\stackrel{{ }_{k}}{\rightleftharpoons}} F_{j}^{i} \varphi^{j} .
$$

Коэффициенты ${ }^{+} k$ и ${ }^{-} k$ имеют смысл интенсивностей взаимодействия.

В системе может происходить $s$ видов различных взаимодействий. Поэтому вместо операторов $I_{j}^{i}$ и $F_{j}^{i}$ будем рассматривать операторы $I_{j}^{i \alpha} \in \mathbb{N}_{0}^{n} \times \mathbb{N}_{0}^{n} \times \mathbb{N}_{+}^{s}$ и $F_{j}^{i \alpha} \in \mathbb{N}_{0}^{n} \times \mathbb{N}_{0}^{n} \times \mathbb{N}_{+}^{s}$ :

$$
I_{j}^{i \underline{\alpha}} \varphi^{j} \underset{{ }_{{ }_{\underline{k}}}}{\stackrel{{ }_{k_{\underline{\alpha}}}}{\rightleftharpoons}} F_{j}^{i \alpha} \varphi^{j}, \quad \underline{\alpha}=\overline{1, s}
$$

здесь греческие индексы задают количество взаимодействий, а латинские - размерность системы. 
Обычно используют диагональные операторы $I$ и $F$. То есть формально их можно представить как вектор для каждой реакции. Тогда система (1) приобретает следующий вид:

$$
I_{j}^{\alpha} \varphi^{j} \stackrel{{ }^{+}{ }_{\underline{\alpha}}}{\underset{{ }_{{ }_{\underline{\alpha}}}}{\rightleftharpoons}} F_{j}^{\alpha} \varphi^{j}
$$

Здесь использованы следующие обозначения:

$$
I_{j}^{\underline{\alpha}}:=I_{j}^{i \underline{\alpha}} \delta_{i}, \quad F_{j}^{\underline{\alpha}}:=F_{j}^{i \underline{\alpha}} \delta_{i}
$$

где $\delta_{\underline{i}}=(1, \ldots, 1)$.

Для комбинаторного подхода также важен оператор изменения состояния:

$$
r_{j}^{i \alpha}=F_{j}^{i \alpha}-I_{j}^{i \alpha}, \quad r_{j}^{\alpha}:=r_{j}^{i \alpha} \delta_{i}=F_{j}^{\underline{\alpha}}-I_{j}^{\alpha} .
$$

\section{IV. КОМБИНАТОРНЫЙ ПОДХОД}

В комбинаторном подходе для описания системы используется основное кинетическое уравнение (master equation), определяющее вероятность перехода в соседнее состояние для марковского процесса [14, 15].

$$
\frac{\partial p\left(\varphi_{2}, t_{2} \mid \varphi_{1}, t_{1}\right)}{\partial t}=\int\left[w\left(\varphi_{2} \mid \psi, t_{2}\right) p\left(\psi, t_{2} \mid \varphi_{1}, t_{1}\right)-w\left(\psi \mid \varphi_{2}, t_{2}\right) p\left(\varphi_{2}, t_{2} \mid \varphi_{1}, t_{1}\right)\right] \mathrm{d} \psi,
$$

где $w(\varphi \mid \psi, t)$ есть вероятность перехода из состояния $\psi$ в состояние $\varphi$ за единицу времени.

Зафиксировав начальные значения $\varphi_{1}, t_{1}$, можно записать данное уравнение для подансамбля:

$$
\frac{\partial p(\varphi, t)}{\partial t}=\int[w(\varphi \mid \psi, t) p(\psi, t)-w(\psi \mid \varphi, t) p(\varphi, t)] \mathrm{d} \psi
$$

При дискретной области определения множества состояний системы ч можно записать (3) (пронумеровав состояния числами $n$ и $m)$ :

$$
\frac{\partial p_{n}(t)}{\partial t}=\sum_{m}\left[w_{n m} p_{m}(t)-w_{m n} p_{n}(t)\right]
$$

где $p_{n}$ - вероятность нахождения системы в состоянии $n$ в момент времени $t, w_{n m}-$ вероятность перехода системы из состояния $m$ в состояние $n$ за единицу времени.

В системе, описываемой одношаговыми процессами, возможны два вида перехода системы из одного состояния в другое, происходящие в результате взаимодействия элементов в прямом направлении $\left(\varphi^{i}+r^{i \alpha}\right)$ с вероятностью ${ }^{+} s_{\underline{\alpha}}\left(\varphi^{k}\right)$ и в обратном направлении $\left(\varphi^{i}-r^{i} \underline{\alpha}\right)$ с вероятностью ${ }^{-} s_{\underline{\alpha}}\left(\varphi^{k}\right)$. А матрица вероятностей переходов может быть записана в виде:

$$
w_{\underline{\alpha}}\left(\varphi^{i} \mid \psi^{i}, t\right)={ }^{+}{ }_{\underline{\alpha}} \delta_{\varphi^{i}, \psi^{i}+1}+{ }^{-}{ }_{\underline{\alpha}} \delta_{\varphi^{i}, \psi^{i}-1}, \quad \underline{\alpha}=\overline{1, s}
$$

где $\delta_{i, j}-$ символ Кронекера.

Таким образом, общий вид основного кинетического уравнения для вектора состояний $\varphi^{i}$, изменяющегося шагами длины $r^{i \alpha}$, принимает вид:

$$
\begin{aligned}
\frac{\partial p\left(\varphi^{i}, t\right)}{\partial t}= & \sum_{\underline{\alpha}=1}^{s}\left\{-s_{\underline{\alpha}}\left(\varphi^{i}+r^{i \underline{\alpha}}, t\right) p\left(\varphi^{i}+r^{i \alpha}, t\right)+\right. \\
& \left.\quad+{ }^{+} s_{\underline{\alpha}}\left(\varphi^{i}-r^{i \alpha}, t\right) p\left(\varphi^{i}-r^{i \alpha}, t\right)-\left[{ }^{+} s_{\underline{\alpha}}\left(\varphi^{i}\right)+{ }^{-} s_{\underline{\alpha}}\left(\varphi^{i}\right)\right] p\left(\varphi^{i}, t\right)\right\} .
\end{aligned}
$$

В комбинаторном подходе собственно основное кинетическое уравнение не используется. Вместо него используют уравнение Фоккера-Планка и уравнение Ланжевена.

Уравнение Фоккера-Планка является частным случаем основного кинетического уравнения и может рассматриваться как его приближённая форма. Его можно получить путём разложения основного кинетического 
уравнения в ряд до членов второго порядка вкючительно. Для этого можно использовать так называемое разложение Крамерса-Мойала [15].

Уравнение Фоккера-Планка имеет следующий вид:

$$
\frac{\partial p\left(\varphi^{k}, t\right)}{\partial t}=-\frac{\partial}{\partial \varphi^{i}}\left[A^{i}\left(\varphi^{k}\right) p\left(\varphi^{k}, t\right)\right]+\frac{1}{2} \frac{\partial^{2}}{\partial \varphi^{i} \partial \varphi^{j}}\left[B^{i j}\left(\varphi^{k}\right) p\left(\varphi^{k}, t\right)\right]
$$

Уравнению Фоккера-Планка соответствует уравнение Ланжевена:

$$
\mathrm{d} \varphi^{i}=a^{i} \mathrm{~d} t+b_{a}^{i} \mathrm{~d} W^{a}
$$

где $a^{i}:=a^{i}\left(\varphi^{k}\right), b_{a}^{i}:=b_{a}^{i}\left(\varphi^{k}\right), \varphi^{i} \in \mathbb{R}^{n}$ - вектор состояний системы, $W^{a} \in \mathbb{R}^{m}-m$-мерный винеровский процесс. Здесь латинскими индексами из середины алфавита обозначаются величины, относящиеся к векторам состояний (размерность пространства $n$ ), а латинскими индексами из начала алфавита обозначаются величины, относящиеся к вектору винеровского процесса (размерность пространства $m \leqslant n$ ).

При этом связь между уравнениями (6) и (7) выражается следующими соотношениями:

$$
A^{i}=a^{i}, \quad B^{i j}=b_{a}^{i} b^{j a} .
$$

Для получения ${ }^{+} s_{\underline{\alpha}}$ и ${ }^{-} s_{\underline{\alpha}}$ используют комбинаторные соображения. Интенсивности перехода в единицу времени ${ }^{+} s_{\underline{\alpha}}$ и ${ }^{-} s_{\underline{\alpha}}$ пропорциональны соответственно числу способов выбора числа размещений из $\varphi^{i}$ по $I_{-}^{i} \underline{\alpha}$ (обозначается как $\left.A_{\varphi \underline{\underline{i}}}^{I \underline{\underline{i}} \underline{\alpha}}\right)$ и по $F_{-}^{i \underline{\alpha}}$ (обозначается как $\left.A_{\varphi \underline{\underline{i}}}^{F^{\underline{i}} \underline{\underline{\alpha}}}\right)$ и определяются выражениями:

$$
\begin{aligned}
& { }^{+} s_{\underline{\alpha}}={ }^{+} k_{\underline{\alpha}} \prod_{\underline{i}=1}^{n} A_{\varphi^{\underline{\underline{i}}}}^{I^{\underline{i} \underline{\alpha}}}={ }^{+} k_{\underline{\alpha}} \prod_{\underline{i}=1}^{n} \frac{\varphi^{\underline{i} !}}{\left(\varphi^{\underline{i}}-I^{\underline{i} \underline{\alpha}}\right) !}, \\
& { }^{-} s_{\underline{\alpha}}={ }^{-} k_{\underline{\alpha}} \prod_{\underline{i}=1}^{n} A_{\varphi \underline{\underline{i}}}^{F^{\underline{i}} \underline{\alpha}}={ }^{-} k_{\underline{\alpha}} \prod_{\underline{i}=1}^{n} \frac{\varphi^{\underline{i}} !}{\left(\varphi^{\underline{i}}-F^{\underline{i} \underline{\alpha}}\right) !} .
\end{aligned}
$$

Поскольку уравнение Фоккера-Планка является следствием разложения в ряд основного кинетического уравнения и отбрасывание малых членов, сделаем в (9) соответствующую замену. А именно комбинации типа $\varphi(\varphi-1) \cdots(\varphi-(n-1))$ заменим на на $(\varphi)^{n}$ :

$$
\begin{aligned}
& { }_{\mathrm{fp}^{+}} s_{\underline{\alpha}}={ }^{+} k_{\underline{\alpha}} \prod_{\underline{i}=1}^{n}\left(\varphi^{\underline{i}}\right)^{I^{\underline{i}} \underline{\underline{\alpha}}}, \\
& \overline{\mathrm{fp}}_{\underline{\underline{\alpha}}} s={ }^{-} k_{\underline{\alpha}} \prod_{\underline{i}=1}^{n}\left(\varphi^{\underline{i}}\right)^{F-\underline{\underline{\alpha}}} .
\end{aligned}
$$

Тогда для уравнения Фоккера-Планка (6) получим формулы для коэффициентов:

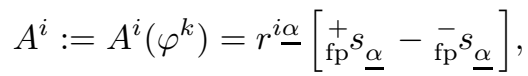

$$
\begin{aligned}
& B^{i j}:=B^{i j}\left(\varphi^{k}\right)=r^{i \alpha} r^{j} \underline{\alpha}\left[{ }_{\mathrm{fp}}^{+} s_{\underline{\alpha}}-{ }_{\mathrm{fp}^{2}}^{-} \underline{\alpha}\right] \text {. }
\end{aligned}
$$

Используя соотношение (요, , из соотношений (10) можно получить коэффициенты для уравнения Ланжевена (7).

\section{V. ОПЕРАТОРНЫЙ ПОДХОД}

Методика применения формализма вторичного квантования для неквантовых систем (статистических, детерминированных) была рассмотрена в целом ряде статей [7, 16 18]. Для записи представления чисел заполнения обычно используют нотацию Дирака.

Переход к пространству чисел заполнения не является унитарным преобразованием. Однако мы можем построить алгоритм перехода. 


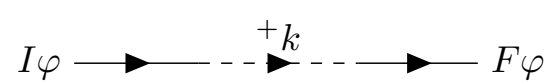

Рис. 1. Прямое взаимодействие

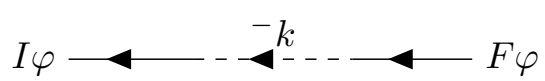

Рис. 2. Обратное взаимодействие

Запишем основное кинетическое уравнение (4) в представлении чисел заполнения. Таким образом, мы будем рассматривать систему, не зависящую от пространственных переменных. Для простоты рассмотрим одномерный вариант.

Обозначим в (4) через $\varphi_{n}$ вероятность обнаружить в системе $n$ частиц:

$$
\varphi_{n}:=p_{n}(\varphi, t)
$$

Состояния $\varphi$ образуют векторное пространство $\mathcal{H}$.

В зависимости от структуры задачи можно ввести скалярные произведения на основе вероятности или на основе моментов [7]. Введём скалярное произведение, исключающее $\left(\langle\mid\rangle_{\text {ex }}\right)$ и включающее $\left(\langle\mid\rangle_{\text {in }}\right)$, считая $|n\rangle$ за базисные векторы:

$$
\begin{aligned}
\langle\varphi \mid \psi\rangle_{\mathrm{ex}} & =\sum_{n} n ! p_{n}^{*}(\varphi) p^{n}(\psi) ; \\
\langle\varphi \mid \psi\rangle_{\mathrm{in}} & =\sum_{n} \frac{1}{k !} n_{k}^{*}(\varphi) n^{k}(\psi) .
\end{aligned}
$$

Здесь через $n_{k}$ обозначены факториальные моменты:

$$
n_{k}(\varphi)=\langle n(n-1) \cdots(n-k+1)\rangle=\left.\frac{\partial^{k}}{\partial z^{k}} G(z, \varphi)\right|_{z=1},
$$

с производящей функцией:

$$
G(z, \varphi)=\sum_{n} z^{n} p_{n}(\varphi)
$$

Введём операторы рождения и уничтожения:

$$
\begin{aligned}
& \pi|n\rangle=|n+1\rangle, \\
& a|n\rangle=n|n-1\rangle
\end{aligned}
$$

с коммутационным соотношением1]:

$$
[a, \pi]=1 .
$$

Из (12) видно, что при выборе скалярного произведения в виде (11) система описывается статистикой БозеЭйнштейна.

В формализме чисел заполнения основное кинетическое уравнение переходит в уравнение Лиувилля:

$$
\frac{\partial}{\partial t}|\varphi(t)\rangle=L|\varphi(t)\rangle
$$

Оператор Лиувилля $L$ удовлетворяет соотношению:

$$
\langle 0| L=0 .
$$

Опишем диаграммную технику в рамках операторного подхода.

Будем записывать схемы взаимодействия в виде диаграмм. Каждой схеме взаимодействия (1) или (2) соответствует пара диаграмм (рис. 11 21) для прямого и обратного взаимодействия соответственно. Диаграмма состоит из следующих элементов.

\footnotetext{
1 Действительно, $a \pi|n\rangle-\pi a|n\rangle=(n+1)|n\rangle-n|n\rangle=|n\rangle$.
} 


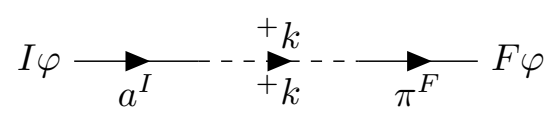

Рис. 3. Прямое взаимодействие

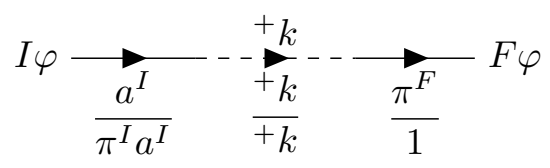

Рис. 5. Прямое взаимодействие, расширенная нотация

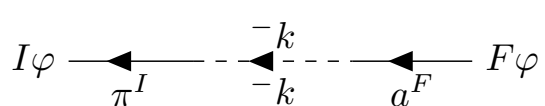

Рис. 4. Обратное взаимодействие

$$
I \varphi \frac{-k}{\frac{\pi^{I}}{1}} \quad \frac{-k}{\frac{-k}{a^{F}}} F \varphi
$$

Рис. 6. Обратное взаимодействие, расширенная нотация

- Входящие линии (на рисунке 1 обозначено сплошной линией). Эти линии направлены к линии взаимодействия. Линия помечается количеством и типом взаимодействующих сущностей. Можно записывать по одной сущности на линию или группировать их.

- Исходящие линии (на рисунке 1 обозначено сплошной линией). Эти линии направлены от линии взаимодействия. Линия помечается количеством и типом взаимодействующих сущностей. Можно записывать по одной сущности на линию или группировать их.

- Линия взаимодействия (на рисунке 1 обозначена пунктирной линией). Направление времени обозначено стрелкой. Линия помечается коэффициентом интенсивности взаимодействия.

Каждой линии приписывается определённый фактор (в зависимости от выбранного подхода). Результирующее выражение получается перемножением этих факторов.

При применении операторного подхода с помощью диаграмм взаимодействия мы получаем оператор Лиувилля. Каждой линии присвоим соответствующий фактор. Результирующий членом будет получен из нормального произведения факторов.

Будем использовать следующие факторы для каждого типа линий (рис. 33).

- Входящая линия. Линия соответствует выводу одной сущности из системы. Следовательно, ей соответствует оператор уничтожения $a$. Очевидно, что комбинированной линии мощности $I$ соответствует оператор $a^{I}$.

- Исходящая линия. Линия соответствует появлению в системе новой сущности. Следовательно, ей соответствует оператор рождения $\pi$. Очевидно, что комбинированной линии мощности $F$ соответствует оператор $\pi^{F}$.

- Линия взаимодействия. Этой линии соответствует собственно коэффициент интенсивности взаимодействия.

То есть, для диаграммы 3 мы получим фактор ${ }^{+} k \pi^{F} a^{I}$. Однако при этом нарушается соотношение (13). Для исправления этого положения мы должны вычесть количество сущностей, вступивших во взаимодействие, помноженное на интенсивность взаимодействия. Тогда получим следующий член оператора Лиувилля:

$$
{ }^{+} k \pi^{F} a^{I}-{ }^{+} k \pi^{I} a^{I}={ }^{+} k\left(\pi^{F}-\pi^{I}\right) a^{I}
$$

Для обратных взаимодействий (рис. 4) используются эти же правила.

Для учёта дополнительного фактора (14) будем использовать расширенные диаграммы (см. рис.5] и 6). 3десь из нормального произведения числителей вычитается нормальное произведение знаменателей.

Таким образом, схеме (1) соответствует оператор Лиувилля:

$$
L=\sum_{\underline{\alpha}, \underline{i}}\left[{ }^{+} k_{\underline{\alpha}}\left(\left(\pi_{\underline{i}}\right)^{F^{\underline{i} \underline{\alpha}}}-\left(\pi_{\underline{i}}\right)^{I-\underline{\underline{\alpha}} \underline{\alpha}}\right)\left(a_{\underline{i}}\right)^{I^{\underline{i} \underline{\alpha}}}+{ }^{-} k_{\underline{\alpha}}\left(\left(\pi_{\underline{i}}\right)^{I^{\underline{i} \underline{\alpha}}}-\left(\pi_{\underline{i}}\right)^{F^{\underline{i} \underline{\alpha}}}\right)\left(a_{\underline{i}}\right)^{F^{\underline{i} \underline{\alpha}}}\right] .
$$




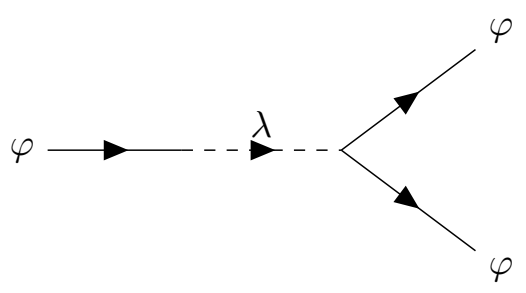

Рис. 7. Первое прямое взаимодействие
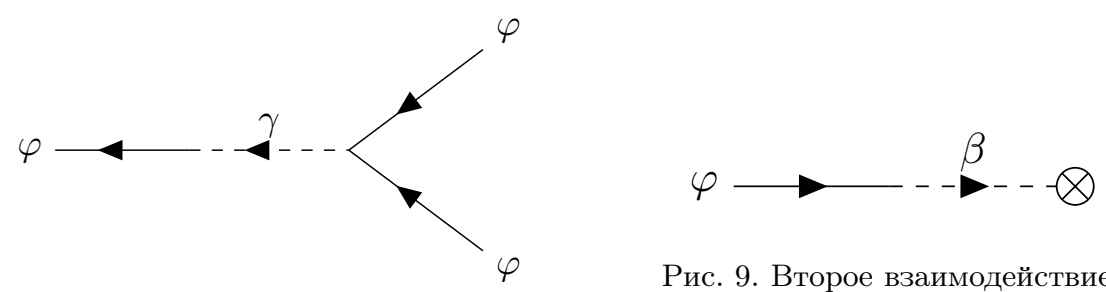

Рис. 9. Второе взаимодействие
Рис. 8. Первое обратное взаимодействие

\section{VI. МОДЕЛЬ ФЕРХЮЛЬСТА}

В качестве демонстрации метода рассмотрим модель Ферхюльста [3, 19, 20], описывающую ограниченный рост. Привлекательность этой модели в том, что она одномерна и нелинейна. Изначально эта модель описывается следующим дифференциальным уравнением:

$$
\frac{\mathrm{d} \varphi}{\mathrm{d} t}=\lambda \varphi-\beta \varphi-\gamma \varphi^{2}
$$

здесь $\lambda$ - коэффициент интенсивности размножения, $\beta$ - коэффициент интенсивности вымирания, $\gamma-$ коэффициент интенсивности уменьшения популяции (обычно рассматривается соперничество особей). Здесь мы оставляем те же обозначения, что и в исходной модели [19].

Построим стохастический вариант данной модели. Запишем схемы взаимодействия:

$$
\begin{gathered}
\varphi \stackrel{\stackrel{\lambda}{\rightleftharpoons}}{\stackrel{\gamma}{\rho}} \varphi, \\
\varphi \stackrel{\beta}{\rightarrow} 0 .
\end{gathered}
$$

Схемам взаимодействия (16) соответствуют диаграммы 7, 8 и 9

Первое соотношение означает, что индивидуум, который съедает единицу пищи, немедленно репродуцируется, в обратную сторону - соперничество между индивидуумами. Второе - смерть индивидуума.

\section{А. Комбинаторный подход}

Определим интенсивности переходов для модели Ферхюльста:

$$
\begin{array}{ccc}
{ }^{+} s_{1}(\varphi)=\lambda \varphi, & { }^{+} s_{1}(\varphi-1)=\lambda(\varphi-1), & { }^{+} s_{1}(\varphi+1)=\lambda(\varphi+1), \\
{ }^{-} s_{1}(\varphi)=\gamma \varphi(\varphi-1), & { }^{-} s_{1}(\varphi-1)=\gamma(\varphi-1)(\varphi-2), & { }^{-} s_{1}(\varphi+1)=\gamma(\varphi+1) \varphi, \\
{ }^{+} s_{2}(\varphi)=\beta \varphi . & { }^{+} s_{2}(\varphi-1)=\beta(\varphi-1) . & { }^{+} s_{2}(\varphi+1)=\beta(\varphi+1) . \\
r^{1}=1, \quad r^{2}=-1 . &
\end{array}
$$

Тогда (на основании (5) ) основное кинетическое уравнение примет следующий вид:

$$
\frac{\partial p(\varphi, t)}{\partial t}=-[\lambda \varphi+\beta \varphi+\gamma \varphi(\varphi-1)] p(\varphi, t)+[\beta(\varphi+1)+\gamma(\varphi+1) \varphi] p(\varphi+1, t)+\lambda(\varphi-1) p(\varphi-1, t) .
$$

Или же, записывая для $\varphi=n$ (см. (4) ):

$$
\begin{aligned}
\frac{\partial p_{n}(t)}{\partial t}:=\left.\frac{\partial p(\varphi, t)}{\partial t}\right|_{\varphi=n} & = \\
& =-[\lambda n+\beta n+\gamma n(n-1)] p_{n}(t)+[\beta(n+1)+\gamma(n+1) n] p_{n+1}(t)+\lambda(n-1) p_{n-1}(t) .
\end{aligned}
$$




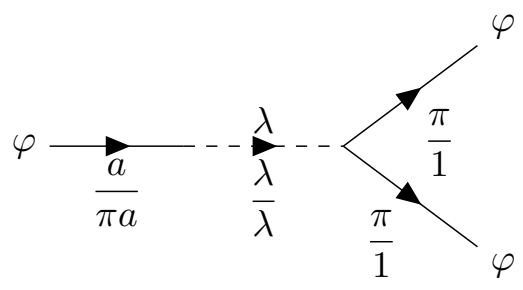

Рис. 10. Первое прямое взаимодействие

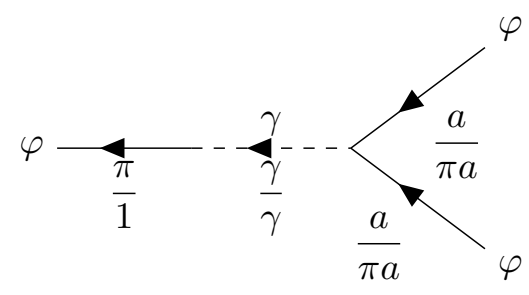

Рис. 11. Первое обратное взаимодействие

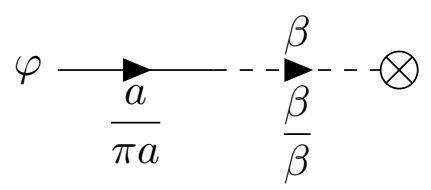

Рис. 12. Второе взаимодействие

\section{В. Операторный подход}

Схемам взаимодействия (16) в операторном подходе соответствуют диаграммы 10, 11 и 12 ,

На основании (16) и (15) получаем оператор Лиувилля:

$$
\begin{aligned}
L=\lambda\left(\pi^{2}-\pi\right) a+\gamma\left(\pi-\pi^{2}\right) a^{2} & +\beta(1-\pi) a= \\
=\lambda\left(\left(a^{\dagger}\right)^{2}-a^{\dagger}\right) a+\gamma\left(a^{\dagger}-\left(a^{\dagger}\right)^{2}\right) a^{2} & +\beta\left(1-a^{\dagger}\right) a= \\
& =\lambda\left(a^{\dagger}-1\right) a^{\dagger} a+\beta\left(1-a^{\dagger}\right) a+\gamma\left(1-a^{\dagger}\right) a^{\dagger} a^{2} .
\end{aligned}
$$

Запишем основное кинетическое уравнение через оператор Лиувилля:

$$
\begin{aligned}
& \frac{\partial p_{n}(t)}{\partial t}=\frac{1}{n !}\langle n|L| \varphi\rangle= \\
&=\frac{1}{n !}\left\langle n\left|-\left[\lambda a^{\dagger} a+\beta a^{\dagger} a+\gamma a^{\dagger} a^{\dagger} a a\right]+\left[\beta a+\gamma a^{\dagger} a a\right]+\lambda a^{\dagger} a^{\dagger} a\right| \varphi\right\rangle= \\
&=-[\lambda n+\beta n+\gamma n(n-1)]\langle n \mid \varphi\rangle+ \\
&+[\beta(n+1)+\gamma(n+1) n]\langle n+1 \mid \varphi\rangle+\lambda(n-1)\langle n-1 \mid \varphi\rangle= \\
&=-[\lambda n+\beta n+\gamma n(n-1)] p_{n}(t)+ \\
&+[\beta(n+1)+\gamma(n+1) n] p_{n+1}(t)+\lambda(n-1) p_{n-1}(t) .
\end{aligned}
$$

Результат (18) полностью совпадает с формулой (17), полученной комбинаторным методом.

\section{VII. ЗАКЛЮЧЕНИЕ}

Описанные методы стохастизации позволяют получать конкретный вид как оператора Лиувилля, так и самосогласованных стохастических дифференциальных уравнений в форме Ланжевена и Фоккера-Планка. Авторы надеются, что предложенная диаграммная техника упростит получение оператора Лиувилля в представлении чисел заполнения.

\section{БЛАГОДАРНОСТИ}

Публикация подготовлена при поддержке Программы РУДН «5-100» и при финансовой поддержке РФФИ в рамках научных проектов № 16-07-00556, 18-07-00567.

[1] Demidova A. V., Korolkova A. V., Kulyabov D. S., Sevastyanov L. A. The Method of Constructing Models of Peer to Peer Protocols // 6th International Congress on Ultra Modern Telecommunications and Control Systems and Workshops (ICUMT). IEEE Computer Society, 2015. - P. 557-562. - 1504.00576.

[2] Velieva T. R., Korolkova A. V., Kulyabov D. S. Designing Installations for Verification of the Model of Active Queue Management Disc 6th International Congress on Ultra Modern Telecommunications and Control Systems and Workshops (ICUMT). IEEE Computer Society, 2015. — P. 570-577. — 1504.02324. 
[3] Feller W. Die Grundlagen der Volterraschen Theorie des Kampfes ums Dasein in wahrscheinlichkeitstheoretischer Behandlung // Acta Biotheoretica - 1939. - Bd. 5, H. 1. - S. 11-40.

[4] Mollison D. Dependence of epidemic and population velocities on basic parameters // Mathematical Biosciences — 1991. dec. - Vol. 107, no. 2. - P. 255-287.

[5] Korolkova A. V., Eferina E. G., Laneev E. B., Gudkova I. A., Sevastianov L. A., Kulyabov D. S. Stochastization Of One-Step Processes In The Occupations Number Representation // Proceedings 30th European Conference on Modelling and Simulation — 2016. — jun. — P. 698-704.

[6] Hnatič M., Eferina E. G., Korolkova A. V., Kulyabov D. S., Sevastyanov L. A. Operator Approach to the Master Equation for the One-Step Process // EPJ Web of Conferences - 2016. - Vol. 108. — P. 58-59. — 1603.02205.

[7] Grassberger P., Scheunert M. Fock-Space Methods for Identical Classical Objects // Fortschritte der Physik — 1980. — Vol. 28, no. 10. - P. 547-578.

[8] Täuber U. C. Field-Theory Approaches to Nonequilibrium Dynamics // Ageing and the Glass Transition. - Berlin, Heidelberg : Springer Berlin Heidelberg, 2005. - Vol. 716. - P. 295-348. — 0511743.

[9] Janssen H.-K., Täuber U. C. The field theory approach to percolation processes // Annals of Physics — 2005. — jan. Vol. 315, no. 1. - P. 147-192. - 0409670.

[10] Mobilia M., Georgiev I. T., Täuber U. C. Fluctuations and correlations in lattice models for predator-prey interaction // Physical Review E. - 2006. — apr. - Vol. 73, no. 4. - P. 040903. — 0508043.

[11] Пенроуз Р., Риндлер В. Спиноры и пространство-время. Два-спинорное исчисление и релятивистские поля. Москва : Мир, 1987. - Т. 1. - С. 527.

[12] Waage P., Gulberg C. M. Studies concerning affinity // J. Chem. Educ. — 1986. — Vol. 63, no. 12. — P. 1044.

[13] Gorban A. N., Yablonsky G. S. Three Waves of Chemical Dynamics // Math. Model. Nat. Phenom. Vol. — 2015. — Vol. 10, no. 5. - P. 1-5.

[14] Ван-Кампен Н. Г. Стохастические процессы в физике и химии. - М. : Высшая школа, 1990.

[15] Гардинер К. В. Стохастические методы в естественных науках. - Мир, 1986.

[16] Doi M. Second quantization representation for classical many-particle system // Journal of Physics A: Mathematical and General - 1976. — Vol. 9, no. 9. - P. 1465-1477.

[17] Doi M. Stochastic theory of diffusion-controlled reaction // Journal of Physics A: Mathematical and General — 1976. Vol. 9, no. 9. - P. 1479-1495.

[18] Peliti L. Path integral approach to birth-death processes on a lattice // Journal de Physique — 1985. — Vol. 46, no. 9. — P. 1469-1483.

[19] Verhulst P. F. Notice sur la loi que la population suit dans son accroissement. — 1838. - Vol. 10. - P. $113-117$.

[20] Feller W. On the theory of stochastic processes, with particular reference to applications // Proceedings of the [First] Berkeley Symposium on Mathematical Statistics and Probability. — 1949. — P. 403-432. 